ORIGINAL ARTICLE

\title{
Beneficial Role of Hydro-alcoholic Seed Extract of Trigonella foenum graecum on Bone Structure and Strength in Menopause Induced Osteopenia
}

\author{
Anjaneyulu K $\mathrm{K}^{1}$, Kumar MR Bhat ${ }^{2 *}$, Srinivasa $\mathrm{SR}^{3}$, Devkar RA ${ }^{4}$, Henry $\mathrm{T}^{5}$
}

\section{OPEN ACCESS}

Citation: Anjaneyulu K, Kumar MR Bhat, Srinivasa SR, Devkar RA, Henry T. Ethiop J Health Sci. 2018; 28(6):787.

doi: http://dx. doi.org/10.4314/ejhs.v28i6.13

Received: April 14, 2018

Accepted: May 21, 2018

Published: November 1, 2018

Copyright: (C) 2018 Anjeneyulu K., et al. This is an open access article distributed under the terms of the Creative Commons Attribution License, which permits unrestricted use, distribution, and reproduction in any medium, provided the original author and source are credited.

Funding: Nil

Competing Interests: The authors declare that this manuscript was approved by all authors in its form and that no competing interest exists.

Affiliation and Correspondence:

${ }^{1}$ Department of Anatomy, Kasturba Medical College, Manipal University, Manipal

${ }^{2}$ Department of Anatomy, Ras Al Khaimah College of Medical Sciences, RAK Medical \& Health Science University, Ras Al Khaimah, UAE

${ }^{3}$ Department of Human and Clinical Anatomy, College of Medicine and Health Sciences, Sultan Qaboos University, Muscat, Oman.

${ }^{4}$ Department of Pharmacognosy, Manipal College of Pharmaceutical Sciences, Manipal University, Manipal, Karnataka

${ }^{5}$ Department of Anatomy, Kasturba Medical College, Manipal University, Manipal

*Email: kumarbhat@rakmhsu.ac.ae
ABSTRACT

BACKGROUND: The current strategies to prevent and treat menopausal osteoporosis are hormone replacement therapy (HRT). However, the long-term use of hormone replacement therapy is limited due to its side-effects. Alternately, use of phytoestrogens has been implicated. Trigonella foenum graecum (TFG) seeds are rich in phytoestrogen and known traditional medicine to treat menopause induced hyperlipidemia. Therefore, in this study, we evaluated the role of dietary TFG seed extract on bone structure and mechanical properties in ovariectomized rats.

METHODS: Twenty four female Wistar rats were randomly allocated into four groups; 1) control, 2) ovariectomized, 3) ovariectomized + TFG seed extract and 4) ovariectomized $+17 \beta$ estradiol. TFG seed extract/17 $\beta$-estradiol was administered for 30 days, 14 days after ovariectomy. After the treatment, right femora were collected to measure the length and biomechanical properties, and left femora were gathered to study the micro architectural changes while tibia were collected to measure the dry weight.

RESULTS: Maximum flexor load to break femur bone was significantly low in ovariectomized rats in comparison with control rats $(P<0.05)$. Supplementation with $T F G$ significantly improved the maximum flexor load $(P<0.05)$ and tibia dry weight $(P<0.01)$ compared to ovariectomized untreated rats. TFG administration also significantly preserved the trabecular $(P<0.01)$ and cortical bone $(P<0.05)$ thickness compared to ovariectomized rats.

CONCLUSION: This study found that dietary intake of TFG seeds can improve the bone structure and biomechanical properties in ovariectomized rats indicating that TFG may be an alternative treatment strategy to prevent the menopause induced osteopenia.

KEYWORDS: Bone, Trigonella foenum graecum, Menopause, Osteoporosis, Phytoestrogen 


\section{INTRODUCTION}

Osteoporosis is a serious worldwide health issue, its frequency is likely to increase in the coming years due to increase in the life span of people. The main characteristic features of osteoporosis are reduced bone mass and alterations in bone microarchitecture. These are the principal causes of bone fragility and fracture (1). Middle-aged and elderly women are being affected by this progressive disease (2). Reduced estrogen level is directly associated with bone resorption in menopausal women (3). Although sufficient dietary calcium is vital in anticipation of osteoporosis (4), in the initial stage of postmenopausal period, $20 \%$ loss of bone mass is due to acute ovarian deficiency (5). To decrease the loss of bone mass in menopause induced osteoporosis is mainly focused on compounds which can favor bone development and prevent osteoclastic bone resorption (6).

In postmenopausal women, estrogen replacement is the most capable therapeutic strategy to limit the bone loss and bone fractures $(7,8)$. Long term hormone replacement therapy (HRT) has its own disadvantages, such as a risk of breast and endometrial cancers $(9,10)$. At present, phytoestrogens are under investigation as natural alternatives to prevent bone loss in women.

Phytoestrogens are the current focus of interest since they are natural plant-derived nonsteroidal compounds with estrogen mimicking activity. Thus, they can be very effective substitutes to reduce bone loss and bone fragility in many conditions. Several studies recommended that a phytoestrogen diet may even protect against menopause related osteoporosis, cardiovascular diseases and breast cancer (11). Trigonella foenum graecum, commonly known as fenugreek, belongs to the Leguminosae family (12). It is widely distributed throughout the world and mainly cultivated in Asia, Africa and Mediterranean countries for the medicinal use of its seeds (13). Fenugreek contains active components such as flavonoids, alkaloids and steroids (14). A steroidal sapogenin component present in fenugreek is diosgenin and has been reported to stimulate the osteoblastic cells in vitro and in vivo $(15,16)$. Hence, we planned to evaluate the role of fenugreek seed extract on postmenopausal osteoporosis/osteopenia.

\section{MATERIALS AND METHODS}

Plant material: Trigonella foenum graecum seeds $(100 \%$ organically grown seeds purchased from Pro Natural, India) were coarse powdered and refluxed for three times, at $85^{\circ} \mathrm{C}$ with $70 \%$ ethanol. The hydro-alcoholic extract was filtered and concentrated under vacuum. Final drying was done using a freeze dryer $(11 \% \mathrm{~W} / \mathrm{W}$ yield was obtained).

Animals: After receiving Institutional Animal Ethics Committee (IAEC) clearance from KMC Manipal, Manipal Academy of Higher Education (Protocol approval number: IAEC/KMC/12/2015), adult healthy female Wistar albino rats of 09-10 months old were allowed to acclimatize for two weeks before starting the experiment. Three animals were housed in one polycarbonate cage. The rats were maintained under standard environmental condition (12 hours day-night cycle with a temperature of $22 \pm 2{ }^{\circ} \mathrm{C}$ ). Animals were provided with a regular pellet diet and water ad libitum.

Experimental design: Rats were allocated randomly into four groups $(n=6)$. The $1^{\text {st }}$ group served as control while the remaining 3 groups were subjected for bilaterally ovariectomy (OVX). Ketamine (50 mg/kg b.w) and xylazine (5 $\mathrm{mg} / \mathrm{kg} \mathrm{b.w}$ ) were injected intraperitoneally (IP) to anesthetize the rats. Animals were aseptically prepared and bilaterally ovariectomized by exploringthe lower abdominal cavity (17). The group 2 animals received normal diet and served as ovariectomized controls (OVX). After two weeks of ovariectomy, group 3 and 4 were supplemented with orally fed Trigonella foenum graecum seed extract $200 \mathrm{mg} / \mathrm{kg} /$ day and subcutaneous injections of $17 \beta$-estradiol $100 \mu \mathrm{g} / \mathrm{kg} /$ day respectively for 30 days. After the supplementation period, all the rats were transcardially perfused with normal saline followed by $10 \%$ formalin. The left and the right femora along with tibia were removed out and freed from the adhered tissues. The right femora were used for measurement of length and 
biomechanical properties. The right side tibia was used for measurement of dry weight. The cleaned left femora were fixed in $10 \%$ neutral buffered formalin solution for microscopic examination of trabecular and cortical bone.

Measurement of length: Right femora were dried and then the length (from tip of the greater trochanter to the lower end of the medial condyle) was measured using a digital Vernier caliper (18).

Measurement of biomechanical properties: Three-point bending test was used to measure the maximum flexor load, by using a Universal testing machine 3366 (Instron Corp, UK). Concisely, the bone was horizontally placed on the material testing machine and the load was applied with $5 \mathrm{~mm} / \mathrm{min}$ speed in the mid of the shaft, until the bone was fractured (19).

Dry weight of the tibia: Right tibia was dried for 48 hours, at $110^{\circ} \mathrm{C}$ in a hot-air oven. Dry weight was measured by using a digital weighing machine (20).

Histomorphometrical analysis: After the fixation with $10 \%$ neutral buffered formalin solution for 5 days at room temperature, the left femora were washed 30 minutes under running tap water. After washing, bones were decalcified in 8\% Hydrochloric Acid/Formic Acid Solution for seven days. Decalcified bones were neutralized with ammonia solution for 2 hours. For paraffin sections, bones were dehydrated in different concentration of ethanol and embedded in paraffin wax. Five $\mu \mathrm{m}$ thick longitudinal sections were taken with a rotary microtome and stained with hematoxylin-eosin. Stained sections were subjected to measurement of trabecular and cortical bone thickness using Olympus Cellsens Imaging Software (1.6 version, USA).

Statistical analysis: Data analysis was done with one-way ANOVA followed by Bonferroni's posthoc test (Graph Pad Prism Version 5.0). Results were expressed as mean $\pm \mathrm{SD}$ and $\mathrm{p}$ value $\leq 0.05$ was expressed as significant.

\section{RESULTS}

Effect of TFG on femora length: Length of the femur was not significant between all the groups (Figure 1).

\section{Length of Femur}

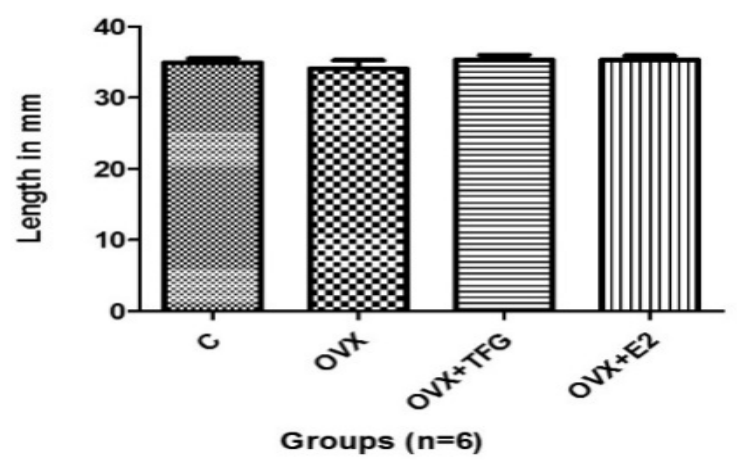

Figure 1. Effect of TFG on a length of the femur. Data was shown asMean $\pm S D$. Femur length was not significant.C: Control, OVX: Ovariectomy, TFG: Trigonella foenum graecum,E2: 17ß-estradiol.

Effect of TFG on biomechanical strength of the femur: Ovariectomized untreated rats took significantly $(p<0.05)$ less flexor load to breakdown the femur bone, compared with control rats. Further, this load was significantly increased in TFG treated rats $(\mathrm{p}<0.05)$ compared to ovariectomy rats. Although estradiol treated rats showed better strength, the result was not statistically significant (Figure 2).

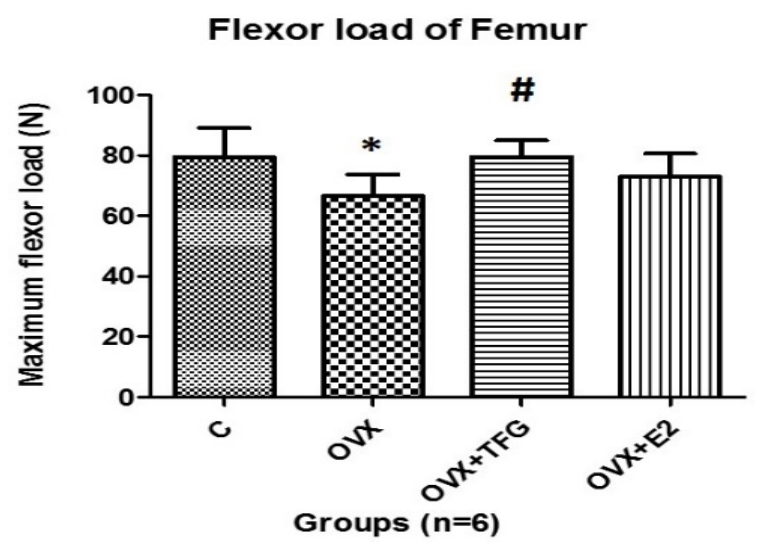

Figure 2. Effect of TFG on Flexor load of Femur. Data was shown as Mean $\pm S D$. C vs. OVX $=*(p<0.05)$; OVX vs. $O V X+F G=\#(p<0.05) . C:$ Control, OVX: Ovariectomy, TFG: Trigonella foenum graecum, E2: $17 \beta$-estradiol. 
Effect of TFG on the dry weight of the tibia: TFG and estradiol treated animals showed significantly more dry weight of tibia in comparison with ovariectomized rats $(\mathrm{P}<0.01$, $\mathrm{P}<0.05)$ respectively. No significant difference was observed between control and ovariectomy groups (Figure 3).

Effect of TFG on cortical bone thickness: Thickness of cortical bone was significantly low inovariectomized rats compared to control rats $(\mathrm{P}<0.05$; Figures 4 (a) and (b)), showing the role of estrogen deficiency on bone mass. This effect was significantly reversed in ovariectomized rats after the treatment with TFG seed extract and estradiol $(\mathrm{P}<0.05, \mathrm{P}<0.05)$ respectively (Figure 4 (a) and (b)).

\section{Effect of TFG on trabecular bone thickness:}

Histomorphometric analysis of epiphyseal region showed thinner trabeculae in ovariectomized rats compared to control rats $(\mathrm{P}<0.05$; Figures 5 (a) and (b)).

\section{Dry weight of Tibia}

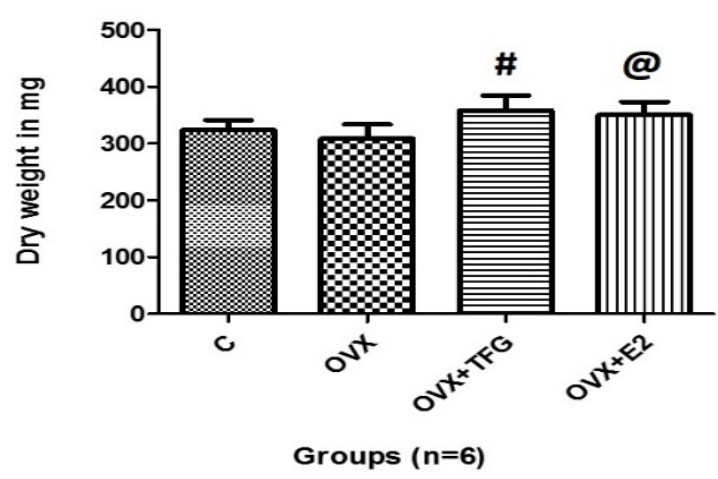

Figure 3. Effect of TFG on dry weight of Tibia. Data was shown as Mean \pm SD.OVX vs. OVX $+F G=\#$ $(p<0.01) ;$ OVXvs. OVX+E2 =@ $(p<0.05) . C:$ Control, OVX: Ovariectomy, TFG: Trigonella foenum graecum, E2: 17ß-estradiol.
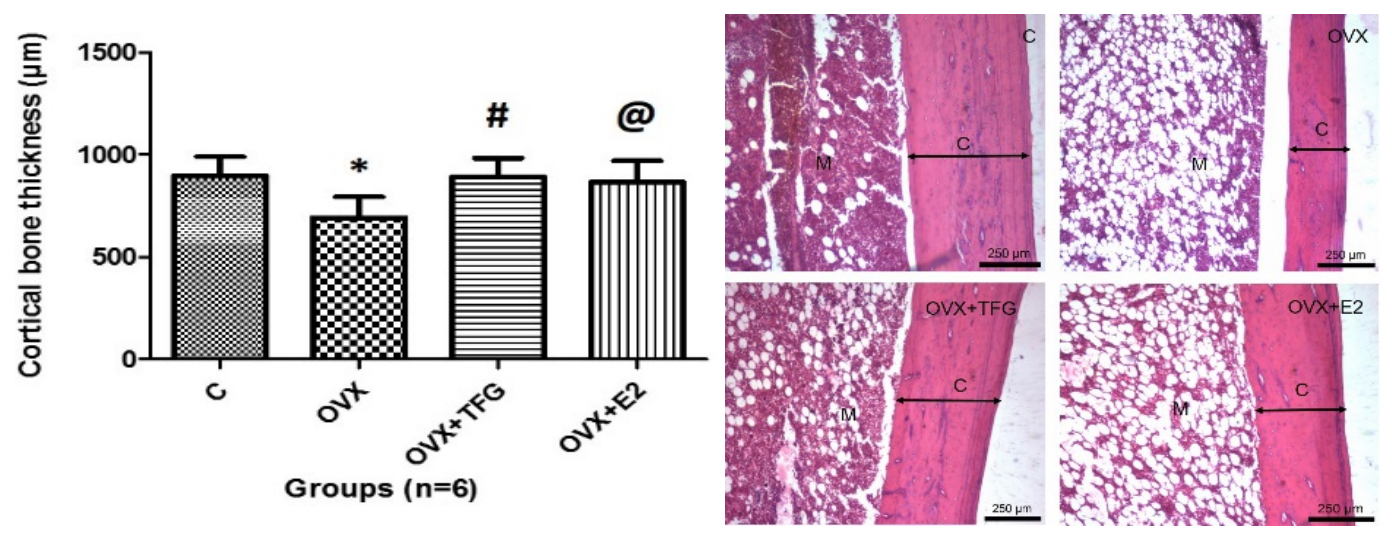

$4 \mathrm{a}$

$4 \mathrm{~b}$

Figure 4. (a) Effect of TFG on mean thickness of cortical bone. Data was shown as Mean $\pm S D$. C vs. OVX: * $p<0.05$; OVX vs. OVX+FG: \# $p<0.05$; OVX vs. OVX+E2: @ p p<0.05.(b) Photomicrograph of cortical bone. Cortical bone thickness was significantly low in ovariectomized rats compared to control rats. On the other hand, TFG and estradiol treated rats showed improved bone thickness compared to OVX rats.C: Control, OVX: Ovariectomy, TFG: Trigonella foenum graecum, E2: 17 $\beta$-estradiol

However, supplementation with TFG and estradiol was significantly improved trabecular thickness compared to ovariectomized rats ( $\mathrm{P}$ $<0.01, \mathrm{P}<0.05$ ) respectively (Figure 5 (a) and (b)). 


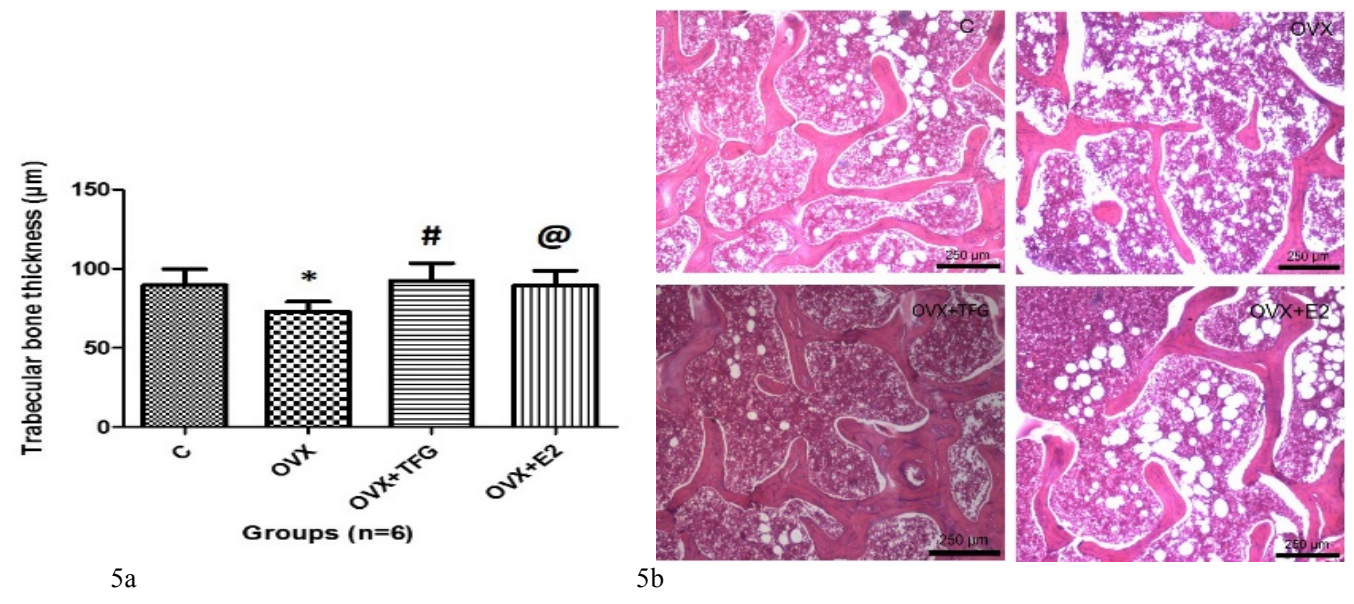

Figure 5. (a) Effect of TFG on mean trabecular bone thickness. Data was shown as Mean $\pm S D$. C vs. OVX: *p<0.05; OVX vs. OVX+FG: \# p<0.01; OVX vs. OVX+E2: @ p<0.05. (b) Photomicrograph of trabecular bone. Ovariectomy group showed thin and less number of trabeculae, compared to normal control rats. Trabecular thickness was significantly improved after the treatment with TFG and estradiolcompared to OVX group.C: Control, OVX: Ovariectomy, TFG: Trigonella foenum graecum, E2: $17 \beta$-estradiol

\section{DISCUSSION}

In our study, we evaluated the efficacy of TFG on biomechanical strength and microarchitecture of bone, by using a standard OVX-induced osteoporosis model. Bone is a highly dynamic structure which shows constant bone remodeling process which is necessary to maintain the skeletal integrity through the bone formation andresorption (3). It is well known that reduction in estrogen level during menopause accelerates the bone resorption, resulting in bone loss leading to osteoporosis (21). Treatment with TFG efficiently reduced trabecular and cortical bone loss and enhanced bone microstructure, biomechanical strength and tibia dry weight.

The findings of this study indicate that TFG supplementation can minimize OVX-induced bone loss. The strength of the bone depends on their composition, mass, geometry, and microstructure (22). In our study, the femoral bone length was not influenced by either ovariectomy or supplementation. TFG Supplementation significantly improved the dry weight of the tibia in ovariectomized rats. This finding correlates with an earlier study reported, showing that the phytoestrogen Red Clover supplementation improved bone dry weight in
OVX rats (23). The biomechanical test reveals that OVX rats significantly exhibit a reduction in three point bending test of the midshaft of the femur. Bone mass reduction, changes in biophysical and bone micro architecture alterations or the combination of all these might be reasons for impaired bone strength (24). TFG treatment displayed greater mechanical bone strength compared to OVX rats. Folwarczna et al., in their study reported that fenugreek seed extract (50 $\mathrm{mg}$ of 4-hydroxy-L-isoleucine $/ \mathrm{kg}$ ) showed better bone strength in OVX rats (25). Our results are consistent with previous studies, which reported phytoestrogenis of lavones from Red clover and anthraquinone derivative from Morindacitrifolia improved bone strength in OVX rats $(23,26)$. This biomechanical assessment exhibited that TFG could improve bone strength in OVX rats.

Histomorphometry allows the assessment of bone remodeling at cellular and tissue levels (27) and, therefore, remains an important tool to evaluate the long-standing properties of therapeutic agents on bone quality and remodeling. Estrogen deficiency accelerates bone loss with a predominance of bone resorption overbone formation in OVX rats (28). The alterations in the microarchitecture of trabecular

DOI: http://dx.doi.org/10.4314/ejhs.v28i6.14 
bone may quickly compromise the strength of bone in ovariectomized rats (29). In this study also, trabecular bone thickness is decreased and changed to rod-like shape in OVX rats. However, TFG treatment significantly improved bone microstructure and prevented the trabecular bone loss. These results are constant with Tantikanlayaporn et al., (2013), who reported that phytoestrogen Diarylheptanoid improved bone structure in OVX rats (30). Especially, in the appendicular skeleton, cortical bone mass plays an important role for the fragility of fractures (31). In our study, TFG treatment improved cortical bone thickness and showed strong linear correlation with bone strength. In agreement with our results, a recent study showed that bisphosphonates treatment improved bone strength and cortical bone thickness in OVX rats (32). The findings of this study displayed the positive effect of TFG seed extract on cortical and trabecular bone thickness. This positive effect of TFG on bone structure and strength might be due to steroidal phytoestrogens present in it.

These preliminary results revealed that dietary supplementation of TFG can protect against ovariectomy induced bone loss in rats. TFG may be of great importance in treating the women with pre and postmenopausal bone disorders without much of the adverse effects. Further evidence via clinical trials and evaluation of exact molecular mechanism may throw light on the further use of TFG seeds as supplementary medicine to treat menopause related disorders.

\section{ACKNOWLEDGEMENTS}

The authors thank Manipal Academy of Higher Education (MAHE) for permitting and providing facilities required to conduct the research.

\section{REFERENCES}

1. Raisz LG. Pathogenesis of osteoporosis: concepts, conflicts, and prospects. Journal of Clinical Investigation, 2005; 115:33183325.

2. Cummings SR, Melton LJ. Epidemiology and outcomes of osteoporotic fractures. Lancet, 2002; 359:1761-1767.

3. Lerner UH. Bone Remodeling in Postmenopausal Osteoporosis. Journal of Dental Research, 2006; 85:584-595.

4. Dawson-Hughes B. Osteoporosis treatment and the calcium requirement. Am J Clin Nutr, 1998; 67:5-6.

5. Avioli LV, Lindsay R. The female osteoporotic syndrome(s). In: Avioli LV, Krane SM, eds. Metabolic bone disease and clinically related disorders. $2^{\text {nd }}$ ed. Philadelphia: WB Saunders; 1990. P. 397451.

6. Downey PA, Siegel MI. Bone Biology and the Clinical Implications for Osteoporosis. Physical Therapy, 2006; 86:77-91.

7. Stevenson M, Jones ML, Nigris ED, Brewer N, Davis S, Oakley J. A systematic review and economic evaluation of alendronate, etidronate, risedronate, raloxifene and teriparatide for the prevention and treatment of postmenopausal osteoporosis. Health Technology Assessment, 2005; 9:1-160.

8. Felson DT, Zhang Y, Hannan MT, Kiel DP, Wilson P, Anderson J. The Effect of Postmenopausal Estrogen Therapy on Bone Density in Elderly Women. New England Journal of Medicine, 1993; 329:141-146.

9. Lacey JV Jr, Mink PJ, Lubin JH, Sherman ME, Troisi R, Hartge P et al. Menopausal hormone replacement therapy and the risk of ovarian cancer. JAMA, 2002; 288:334-341.

10. Chlebowski RT, Anderson GL, Gass M, Lane DS, Aragaki AK, Kuller LH et al. Estrogen plus progestin and breast cancer incidence and mortality in postmenopausal women. JAMA, 2010; 304:1684-1692.

11. Messina MJ, Wood CE. Soy isoflavones, estrogen therapy, and breast cancer risk: analysis and commentary. Nutr $J$ 2008; 7:17. 
12. Krishnaswamy K. Traditional Indian spices and their health significance. Asia Pac J Clin Nutr, 2008; 17:265-268.

13. Petropoulos G.A. "Fenugreek -The genus Trigonella". $1^{\text {st }}$ ed. Taylor and Francis, London and New York. 2002. P. 1-127.

14. Ahirwar D, Ahirwar B, Kharya MD. Evaluation of antifertility activity of Trigonella foenum graecum seeds. Der Pharmacia Sinica, 2010; 1:33-39.

15. Alcantara EH, Shin MY, Sohn HY, Park YM, Kim T, Lim JH et al. Diosgenin stimulates osteogenic activity by increasing bone matrix protein synthesis and bonespecific transcription factor Runx2 in osteoblastic MC3T3-E1 cells. $J$ Nutr Biochem, 2011; 22:1055-1063.

16. Shishodia S and Aggarwal BB. Diosgenin inhibits osteoclastogenesis, invasion, and proliferation through the down regulation of Akt, I $\kappa \mathrm{B}$ kinase activation and NF- $\kappa \mathrm{B}-$ regulated gene expression. Oncogene, 2006; 25:1463-1473.

17. Parhizkar S, Ibrahim R, Latiff LA. Incision choice in laparatomy: a comparison of two incision techniques in ovariectomy of rats. World Apple Sci J, 2008; 4:537-540.

18. Shivakumar K, Mukund H, Rabin $P$. Evaluation of antiosteoporotic activity of root extract of Rubiacordifoliain ovariectomized rats. Int J Drug Dev Res, 2012; 4:163-1672.

19. Folwarczna J, Pytlik M, Zych M,Cegieła U, Kaczmarczyk-Sedlak I, Nowinska B, Sliwinski L. Favorable effect of moderate dose caffeine on the skeletal system in ovariectomized rats. MolNutr Food Res, 2013; 57:1772-1784.

20. Reddy NP, Lakshmana M, Udupa UV. "Antiosteoporotic activity of OST6(Osteocare), a herbomineral preparation in calcium deficient ovariectomized rats."Phytotherapy Research, 2004; 18:2529.

21. Sample SJ, Racette MA, Hao Z, Thomas CF, Behan M, Muir P. Functional adaptation in female rats: the role of estrogen signaling. PLOS ONE 2012; 7:e43215.
22. Clarke B. Normal bone anatomy and physiology. Clin J Am Soc Nephrol, 2008; 3:131-139.

23. Occhiuto F, De Pasquale R, Guglielmo G, Palumbo DR, Zangla G, Samperi S et al. Effects of PhytoestrogenicIsoflavones from Red Clover (TrifoliumpratenseL.) on Experimental Osteoporosis. Phytother Res, 2007; 21:130-134.

24. Fonseca H, Moreira-Gonçalves D, Coriolano HJ, Duarte JA. Bone quality: The determinants of bone strength and fragility. Sport Med 2014; 44:37-53.

25. Folwarczna J, Zych M, Nowinska B, Pytlik $M$. "Effects of fenugreek (Trigonella foenum-graecum L.) seed on bone mechanical properties in rats." Eur Rev Med Pharmacol Sci, 2014; 18:1937-47.

26. Joy A, Chaitra N, Ashok M, Handral M. Antiosteoporotic activity of anthraquinone isolated from morindacitrifolia fruits in rats. Asian J Pharm Clin Res, 2016; 9:209-213.

27. Rupprecht M, Pogoda P, Mumme M, Rueger $\mathrm{JM}$, Puschel K, Amling $\mathrm{M}$. Bone microarchitecture of the calcaneus and its changes in aging: a histomorphometric analysis of 60 human specimens. $J$ Orthop Res, 2006; 24:664-674.

28. Peng S, Xia R, Fang H, Li F, Chen A, Zhang G, Qin L. Effect of Epimedium-derived Phytoestrogen on Bone Turnover and Bone Microarchitecture in OVX-induced Osteoporotic Rats. J Huazhong Univ Sci Technol, 2008; 28:167-170.

29. Tezval M, Biblis M, Sehmisch S, Schmelz U, Kolios L, Rack $\mathrm{T}$ et al. Improvement of Femoral Bone Quality After LowMagnitude, High-Frequency Mechanical Stimulation in the Ovariectomized Rat as an Osteopenia Model. Calcified Tissue International, 2011; 88: 33-40.

30. Tantikanlayaporn D, Wichit P, Weerachayaphorn J, Chairoungdua A, Chuncharunee A, Suksamrarn A, Piyachaturawat P. Bone Sparing Effect of a Novel Phytoestrogen Diarylheptanoid from 
Curcuma comosaRoxb in Ovariectomized Rats. PLoS ONE, 2013; 8:e78739.

31. Zebaze RM, Ghasem-Zadeh A, Bohte A, Iuliano-Burns S, Mirams M, Price RI et al. Intracortical remodeling and porosity in the distal radius and post-mortem femurs of women: a cross-sectional study. Lancet, 2010;375:1729-1736.
32. Camargos GV, Bhattacharya P, Van Lenthe GH, Del Bel Cury AA, Naert I, Duyck J, Vandamme K. Mechanical competence of ovariectomy-induced compromised bone after single or combined treatment with highfrequency loading and bisphosphonates. Sci Rep, 2015; 5:10795.

DOI: http://dx.doi.org/10.4314/ejhs.v28i6.14 